\title{
Rheological and thermal analysis of the filling stage of injection moulding
}

\author{
A. Szücs ${ }^{*}$, K. Belina \\ Department of Polymer and Rubber Technology, Faculty of Mechanical Engineering and Automation, Kecskemét \\ College, Izsáki út 10., H-6000 Kecskemét, Hungary
}

Received 14 October 2011; accepted in revised form 7 March 2012

\begin{abstract}
Flow conditions are different in the cavity of the injection mould from the capillary flow of a laboratory rheological instrument. An injection moulding slit die rheometer (Rheo-mould) was designed with a series of slit and orifice dies. Four pressure sensors were built in the stationary side of the mould, therefore the pressure could be measured at four different places. A changeable slit die insert was designed in the moving side. The shear stress and the shear rate can be calculated from the pressure gradient and from the flow rate of the melt, respectively. Flow curves of low density polyethylene were determined using Bagley, Rabinowitsch and Mooney corrections. The results were compared to the flow curves determined by Göttfert and Haake capillary equipments. It was found that the agreement between the methods is excellent.
\end{abstract}

Keywords: rheology, injection moulding, cavity pressure, mould filling

\section{Introduction}

Determination of rheological properties of molten polymers is a considerably studied field of Polymer Physics. Knowledge of real viscosity of polymer melt in the injection moulding process is extremely important. The flow of polymers is a complex process, as the viscosity of plastics, apart from temperature and pressure, depends on the molecular mass, molecular mass distribution and on the deformation rate. These make plastic processing rather difficult. During the flow in nozzle, runner system and in thin walled cavities of injection moulds, both shear and elongation deformation processes are developed, and the deformation rates are generally high. Many laboratory instruments can be found on the market but only a few of them are suitable for measuring the flow properties of polymeric material in the processing environment. On-line extrusiometers are wide-spread instruments, but injec- tion moulding machines are hardly used for rheological tests [1-6].

One of the main goals of our research is to develop a special injection mould which is suitable to determine the rheological properties of polymers at a high deformation rate. In the first stage of the research, two pressure sensors were built into a standard injection mould. Basic measurements and calculations were carried out by it. Then a spiral injection mould was designed, and after some success, it was upgraded to a changeable slit die system. In the final set-up, most of the important parameters can be controlled $[7,8]$.

The importance of the results is to get reliable data for the simulation of the injection moulding process. Reliability of filling simulations depends mainly on the following four factors [7]: input data, process parameters, software applications and numerical models. In particular, among the processing param-

\footnotetext{
${ }^{*}$ Corresponding author, e-mail: szucs.andras@gamf.kefo.hu
} (c) BME-PT 
eters, the rheological characteristics of polymer melts have the largest influence on the filling simulation.

\section{Theoretical background and calculations}

There are two approaches to describe flow behaviour of a rheologically complex fluid: continuum mechanics and molecular approach. The molecular approach is rather complex, as molecular structure and molecular motions are considered to describe the relationships. Considering the material as a continuum, stress-strain relationships can be calculated by mathematical equations based on the theories of continuum mechanics. In principle, there are six independent components of stress that must be specified to completely describe the state of stress. However, in simple steady shear flow, fewer number of stress components is necessary. For example, stress components in a cube are shown in Figure 1, and the corresponding stress and deformation rate tensors are shown in Equation (1) and Equation (2), respectively:

$$
\begin{gathered}
\tau=\left[\begin{array}{ccc}
\tau_{\mathrm{zz}} & \tau_{\mathrm{zy}} & 0 \\
\tau_{\mathrm{yz}} & \tau_{\mathrm{yy}} & 0 \\
0 & 0 & \tau_{\mathrm{xx}}
\end{array}\right] \\
\dot{\gamma}=\left[\begin{array}{ccc}
0 & \dot{\gamma} & 0 \\
\dot{\gamma}_{\mathrm{yz}} & 0 & 0 \\
0 & 0 & 0
\end{array}\right]
\end{gathered}
$$

where $\tau$ is the shear stress tensor, $\dot{\gamma}$ is the shear rate tensor, $x, y$ and $z$ shows the directions. $\tau_{\mathrm{zz}}$ means the shear stress acting on the surface perpendicular to the $z$ axis and showing in $z$ direction.

Different kinds of measuring systems can be used for rheological measurements. Mostly simple shear flow is carried out in capillary or in slit die. In steady shear flow there are no more than three independent material functions needed for correlating the stress quantities of rheological significance to the shear
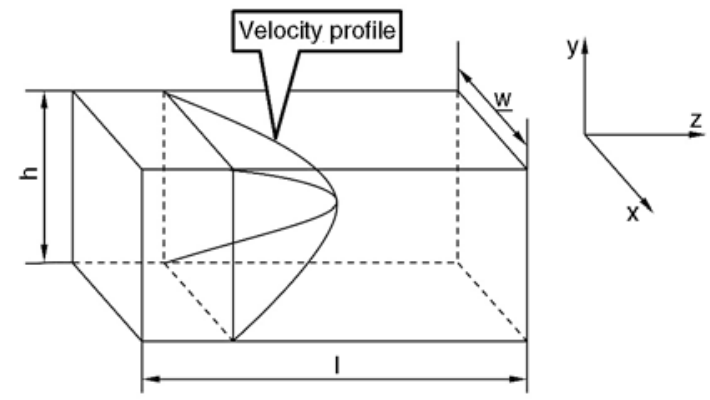

Figure 1. Shear flow in a slit die. (w: width of the die; $h$ : height of the die, $l$ : flow length) rate. These viscosity functions are given by Equations (3-5):

$$
\begin{array}{ll}
\tau_{12}=\tau(\dot{\gamma}), & \eta(\dot{\gamma})=\frac{\tau(\dot{\gamma})}{\dot{\gamma}} \\
\tau_{11}-\tau_{22}=N_{1}(\dot{\gamma}), & \xi_{12}(\dot{\gamma})=\frac{N_{1}(\dot{\gamma})}{\dot{\gamma}^{2}} \\
\tau_{22}-\tau_{33}=N_{2}(\dot{\gamma}), & \xi_{23}(\dot{\gamma})=\frac{N_{2}(\dot{\gamma})}{\dot{\gamma}^{2}}
\end{array}
$$

in which $\eta(\dot{\gamma}), N_{1}$ and $N_{2}$ are called material functions. $\eta(\dot{\gamma})$ defines the shear dependent viscosity, $\xi_{12}$ defines the first normal stress function, $\xi_{23}$ defines the second normal stress function [9].

In the measurements by capillary rheometers, the flow rate (shear rate) is controlled and the pressure drop (shear stress) is measured. The apparent values can be calculated from the primary data, but some corrections must be made for the determination of real functions.

In the calculations, apparent values are used. The apparent shear rate, shear stress and viscosity can be calculated if slit die is used by Equations (6-8):

$\dot{\gamma}_{\text {app }}=\frac{6 Q}{h^{2} w}$

$\tau_{\text {app }}=\frac{h \Delta p}{2 l}$

$\eta_{\text {app }}=\frac{\tau_{\text {app }}}{\dot{\gamma}_{\text {app }}}$

where $Q$ is the volumetric flow rate, $h$ is the height of the die, $w$ is the width of the die, $l$ is the flow length, $\Delta p$ is the pressure drop, $\tau$ is the shear stress, $\dot{\gamma}$ is the shear rate.

In order to obtain accurate experimental results, the height-to-width ratio $(h / w)$ of the slit die should be near to zero $(w>>h)$, because the existing theoretical equations converting $Q$ and $\Delta p / l$ to shear rate and shear stress, respectively, are based on the assumption that the velocity does not depend on lateral position. Approaching $w / h$ ratio to zero, the edges make negligible contribution to the pressure drop. In this case the corrected shear rate and shear stress are calculated by Equations (9-11) [10]:

$\tau_{\mathrm{w}}=\frac{\Delta p h}{2 l}\left(\frac{1}{\frac{h}{w}+1}\right)$ 
where $h$ is the height and $w$ is the width of the die. $\Delta p$ is the pressure drop, $l$ is the measured flow length (Equation (10)):

$\dot{\gamma}=\frac{2}{3}\left(\frac{6 Q}{h^{2}}\right)\left(\frac{b}{f}+\frac{a}{f} \frac{1}{n}\right)$

where $Q$ is volume rate, $a, b, f$ are correction factors, $n$ is the power law index (Equation (11)):

$n=\frac{\mathrm{d} \log \tau_{\mathrm{f}}}{\mathrm{d} \log \dot{\gamma}_{\mathrm{f}}}$

Some material might slip on the wall of the die. Figure 2 shows the velocity profile of the melt if it slips. Using different slit die cross sections but same flow length, the velocity of the wall slip can be determined [11].

The total volumetric flow rate $\left(Q_{\mathrm{T}}\right)$ can be calculated by Equation (12):

$Q_{\mathrm{T}}=\frac{h^{3} w}{6} \dot{\gamma}$

The volumetric flow rate by the slip $\left(Q_{\text {slip }}\right)$ is given by the Equation (13):

$Q_{\text {slip }}=w h v_{\text {slip }}$

where $v_{\text {slip }}$ is the velocity of wall slip.

The apparent shear rate can be plotted as function of $1 / h$ and the wall slip velocity can be calculated from the slope of the curve described in Equation (14):

$\dot{\gamma}_{\text {app }}=\dot{\gamma}_{\text {true }}+\frac{6 v_{\text {slip }}}{h}$

According to Equation (7), the pressure gradient is a linear function of flow length. If it is not valid, Bagley correction should be applied.

The viscosity of molten polymer is really high, basically it is between $10 \ldots 10.000 \mathrm{~Pa} \cdot \mathrm{s}$ in injection moulding or extrusion process. Due to the high viscosity, the dissipation heat and the effect of pressure

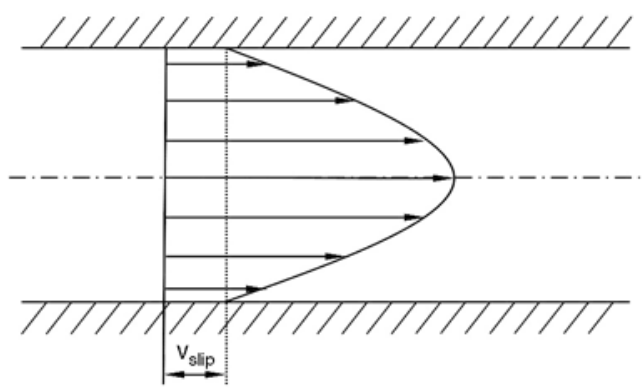

Figure 2. Velocity profile of the melt are not negligible. The average temperature rising $(\Delta T)$ can be calculated by Equation (15):

$\Delta T=\frac{\Delta p}{\rho c_{\mathrm{p}}}$

where $\Delta p$ is the pressure drop, $\rho$ is the density, $c_{\mathrm{p}}$ is the specific heat of the material. Equation (15) assumes that there is no heat exchange between the material and the mould (wall of the die). In real cases there is some heat transfer between the mould and the polymer melt. This transfer depends on the temperature difference, therefore changing the mould temperature it is possible to influence the heat exchange rate. Dimensionless numbers (Graetz-, Nahme- Brinkman-number) are used to characterise the thermal conditions of the flow of polymer melt. Graetz-number ( $G z$, Equation (16)) [12] compares the heat transfer in the flow direction to the perpendicular direction:

$G z=\frac{2 \rho c_{\mathrm{p}} Q h}{\lambda w l}$

where $\rho$ is the density of the material, $c_{\mathrm{p}}$ the specific heat capacity, $\lambda$ is coefficient of thermal conduction. If $G z>>1$, the material temperature in the calculation and the incoming material temperature are the same [13].

Nahme-number ( $\mathrm{Na}$, Equation (17)) compares the temperature rising by dissipation heat to the temperature influence to the viscosity:

$N a=\frac{\eta Q^{2} \alpha_{\eta}}{4 k h^{2} w^{2}}$

where $\alpha_{\eta}$ is temperature coefficient of viscosity.

If $N a>1$, the dissipation heat has significant effect on the viscosity.

Brinkman-number ( $B r$, Equation (18)) compares the dissipation heat to the perpendicular heat transfer:

$B r=\frac{\eta Q^{2}}{4 k h^{2} w^{2}\left|T_{\text {in }}-T_{\text {wall }}\right|}$

where $T_{\text {in }}$ is the incoming material temperature, $T_{\text {wall }}$ is the temperature of the wall of the cavity. If $B r>1$, the dissipation is the major process, therefore the temperature drop of the material is negligible. If the mould temperature and the material temperature are the same, the Brinkman-number is infinite. 
According to Laun studies [13-14], the real pressure drop (allowing for the dissipation heat and the effect of the pressure) can be calculated by Equation (19):

$$
\Delta p \approx \Delta p_{0} \exp \left(\beta_{\eta} p_{1}\right)\left[1-\left(\beta_{\eta}+\alpha_{\eta} \varepsilon_{\mathrm{p}}\right) \frac{\Delta p_{0}}{2} \exp \left(\beta_{\eta} p_{1}\right)\right]
$$

where $\Delta p_{0}$ stands for the pressure loss without pressure and temperature effects, $\beta_{\eta}$ pressure coefficient of viscosity $\alpha_{\eta}$ temperature coefficient of viscosity, $\Delta p$ is the measurable pressure difference $(\Delta p=$ $\left.p_{1}-p_{2}\right)$.

$$
\varepsilon_{\mathrm{p}}=\frac{1}{\rho_{0}\left(c_{\mathrm{p}}+\frac{\Lambda}{\dot{m}}\right)}
$$

Equation (20) represents a dissipative heating coefficient $\left(\varepsilon_{\mathrm{p}}\right)(\Lambda$ lump heat transfer coefficient summarising all types of heat loss out of the melt). The adiabatic case (insulated walls) is got by setting $\Lambda=$ $0, \dot{m}$ represents the mass flow rate, $\rho_{0}$ is the melt density [13].

\section{Experimental}

\subsection{Materials}

TIPOLEN FA2210 (Tisza Chemical Group PLC, Tiszaújváros, Hungary) low-density polyethylene material was used for the measurements. This material is recommended for blow moulding technology, so the viscosity of the material can be measured easily during shear and the deformation caused by elongation. The characteristics of the PE are summarised in Table 1.

Table 1. Main properties of the material

\begin{tabular}{|l|l|}
\hline \multicolumn{1}{|c|}{ Properties } & Value \\
\hline MFI $\left(190^{\circ} \mathrm{C} ; 2,16 \mathrm{~kg}\right)$ & $0.3 \mathrm{~g} / 10 \mathrm{~min}$ \\
\hline Density $\left(23^{\circ} \mathrm{C}\right)$ & $0.922 \mathrm{~g} / \mathrm{cm}^{3}$ \\
\hline Maximum viscosity $\left(190^{\circ} \mathrm{C}\right)$ & $90000 \mathrm{~Pa} \cdot \mathrm{s}$ \\
\hline Apparent activation energy of flow & $31.5 \mathrm{~kJ} / \mathrm{mol}$ \\
\hline
\end{tabular}

\subsection{Measuring system}

An ARBURG Allrounder 270 C 350-70 standard injection moulding machine was used in the experiment. The most important machine parameters are listed in Table 2.

There are some instrumented injection moulds [1-5] but the one developed by us is basically different
Table 2. The most important machine parameters

\begin{tabular}{|l|l|}
\hline \multicolumn{1}{|c|}{ Parameters } & \multicolumn{1}{c|}{ Value } \\
\hline Injection rate $(Q)$ & $5 \ldots 90 \mathrm{~cm}^{3}$ \\
\hline Injection pressure $($ pinjection $)$ & $1500 \mathrm{bar}$ \\
\hline Material temperature $\left(T_{\text {mat }}\right)$ & $180 \ldots 220^{\circ} \mathrm{C}$ \\
\hline Mould temperature $\left(T_{\text {mould }}\right)$ & $30 \ldots 220^{\circ} \mathrm{C}$ \\
\hline Screw rotation speed $(n)$ & $150 \mathrm{~mm} / \mathrm{s}$ \\
\hline Back pressure $\left(p_{\text {back }}\right)$ & $20 \mathrm{bar}$ \\
\hline Switch-over point $\left(s_{\text {switch }}\right)$ & $1 \mathrm{~cm}^{3}$ \\
\hline Packing time $\left(t_{\text {pack }}\right)$ & $0 \mathrm{~s}$ \\
\hline
\end{tabular}

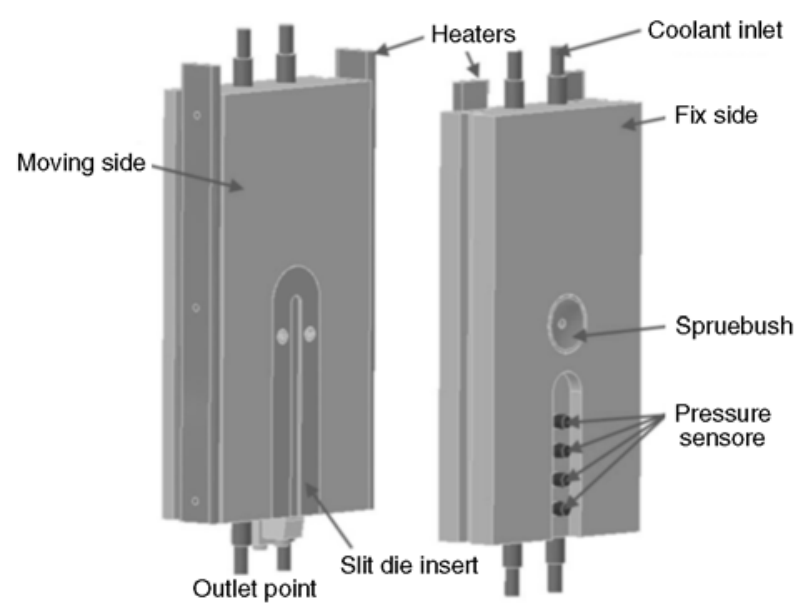

Figure 3. Active plates and the accessories of the system

from them. The material enters in the centreline of the mould from the sprue bush and goes to the parting line. There is a quick-change slit die system in the moving side. The material flow through the die and came out at the end of it. Three pressure sensors (Kistler 6157BD) and one P-T combo sensor (Kistler 6190A) were built into the fixed side. The mould temperature was controlled by cooling fluid to $90^{\circ} \mathrm{C}$, and an electric heating system was used above $90^{\circ} \mathrm{C}$. The drawing of the mould can be seen in Figure 3.

Figure 4 shows the positions of the sensors. The dimensions of the dies used in the experiments are listed in the Table 3 . The width of the dies was the same, $15 \mathrm{~mm}$.

A virtual instrument was developed by LabView software environment for data processing. It can control the database and calculate the rheological properties from the measured pressure in Windows $\mathrm{XP}$ environment. The applied sampling rate was $0.001 \mathrm{sec}$ in the measurements. This relatively high sampling rate is necessary to study the melt fracture effect. The schematic drawing of the electronic system is shown in Figure 5. 


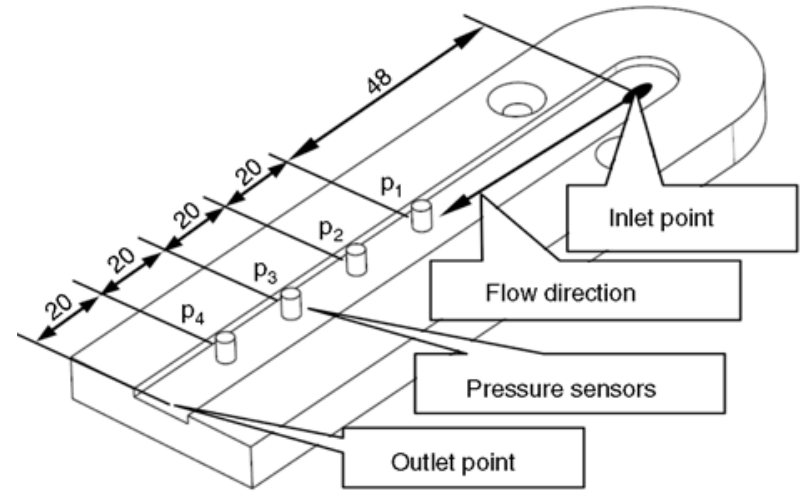

Figure 4. Slit die insert

Table 3. Geometry of the dies

\begin{tabular}{|l|r|r|r|r|r|r|}
\hline \multicolumn{1}{|c|}{ No. of slit die } & \multicolumn{1}{|c|}{$\mathbf{1 .}$} & $\mathbf{2 .}$ & \multicolumn{1}{|c|}{$\mathbf{3 .}$} & \multicolumn{1}{|c|}{} & \multicolumn{1}{|c|}{} & \multicolumn{1}{c|}{$\mathbf{.}$} \\
\hline Height $(h)[\mathrm{mm}]$ & 2 & 3 & 4 & 2 & 2 & 2 \\
\hline Flow length $(l)[\mathrm{mm}]$ & 80 & 80 & 80 & 45 & 65 & 80 \\
\hline Width $(w)[\mathrm{mm}]$ & 15 & 15 & 15 & 15 & 15 & 15 \\
\hline
\end{tabular}

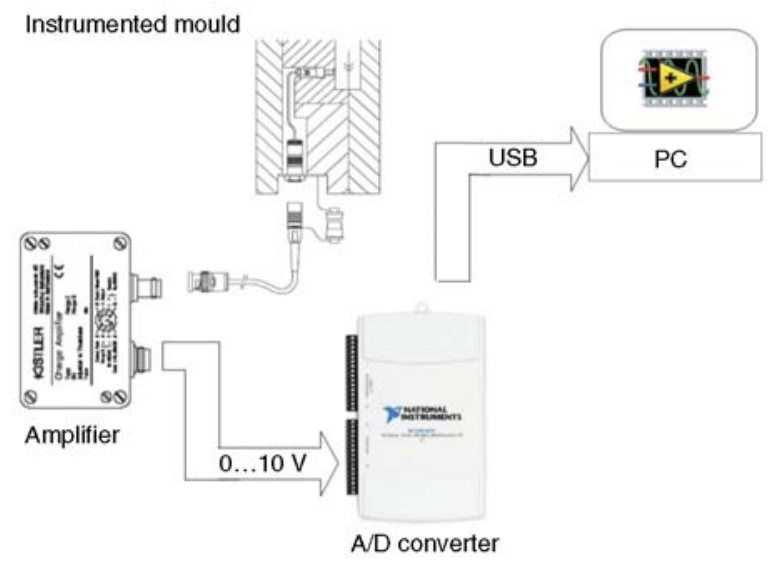

Figure 5. Signal transducer system

The measured four pressure curves and the pressure differences are plotted as a function of time in Figure 6. It can be seen that the cavity filling has two different phases. The material flows inside of the cavity in the first stage. The pressures increase continuously until the melt front reaches the outlet point.

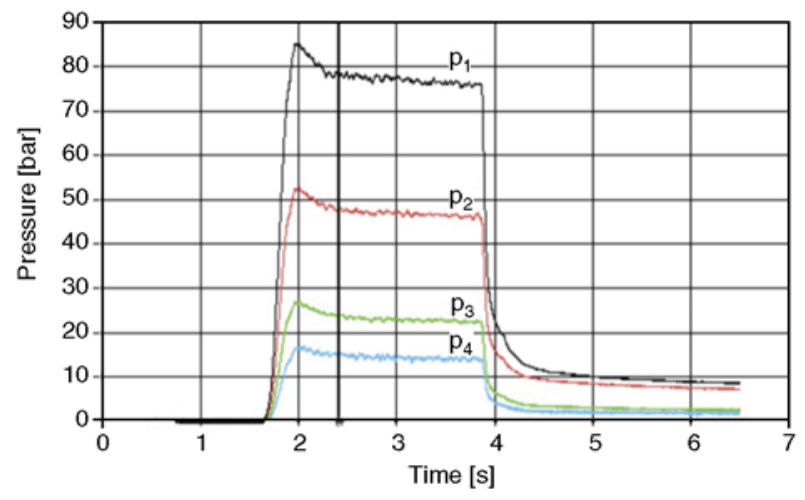

Figure 6. Measured pressure curves
The molten polymer flows out freely from this time and the measured pressures are roughly constant. These constant pressures were used in the calculations. The pressure drops close to the end of the cavity between $p_{3}$ and the $p_{4}$ pressure were smaller than the former pressure drops. It can be explained by the end effect of the die.

Minimum three injections were made by each set up and the pressure curve was recorded if the standard deviation was less than 5\%. The average deviation was less than $1 \%$.

\section{Results and discussion}

\subsection{Investigation of the flow}

The measuring range was $500-90001 / \mathrm{s}$. Three different temperatures were investigated. The calculated apparent flow curves are shown in Figure 7. These curves correspond to the curves of pseudo plastic materials: increasing the shear rate, the viscosity of the melt decreases.

Correction of cross section showed that the apparent shear rate increased (Rabinowitsch correction), and the apparent shear stress decreased (Figure 8).

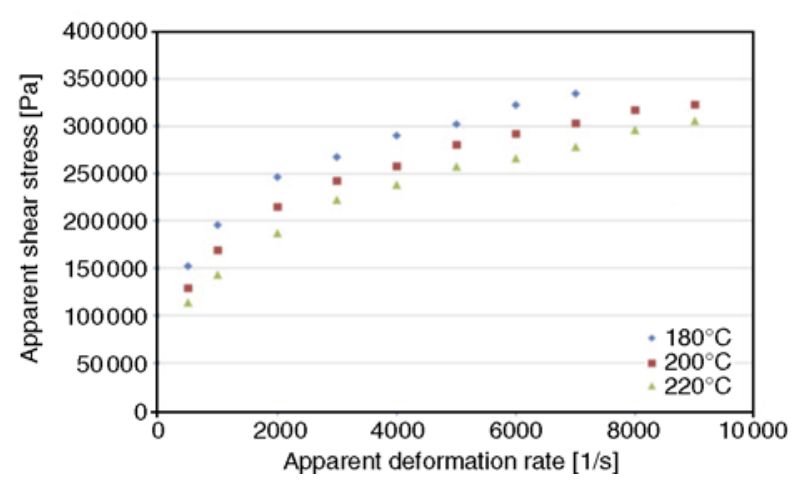

Figure 7. Effect of the cross section correction

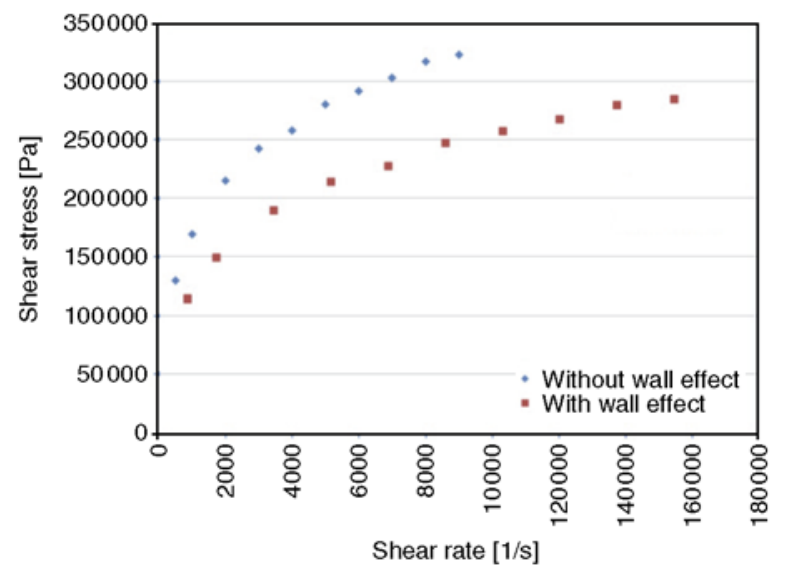

Figure 8. Flow curves calculated with and without the wall effect 


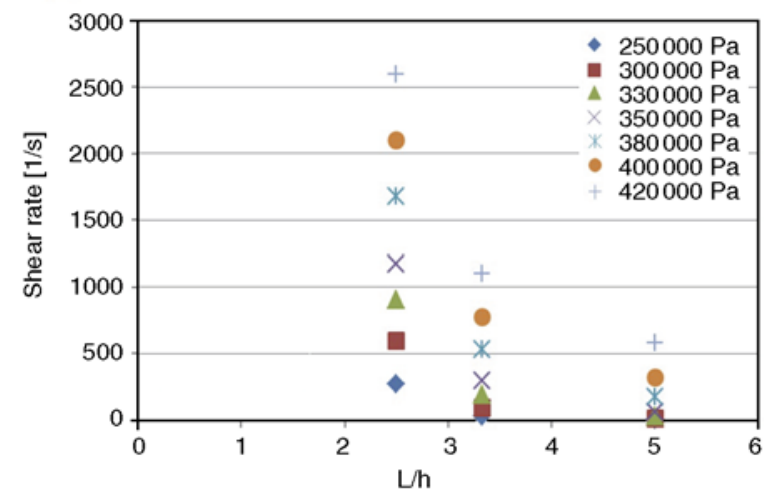

Figure 9. Mooney plots

The Mooney correction was calculated by the measurement of die inserts No 1,2,3. It was found that the slope of the Mooney lines were negative so there is no slip on the wall (Figure 9)

The Bagley correction was calculated by the measurement with inserts No. 4, 5 and 6 (Figure 10). It can be seen that the smallest $1 / h$ ratio was 15 . It is rather far from the ideal $1 / \mathrm{h}$ range (close to 0 ), however the regression constants of the lines are above 0,98 . The calculated values are summarised in Table 4.

The apparent values were corrected and the real viscosity curves are shown in Figure 11. For comparison, the material was tested by two other kinds of

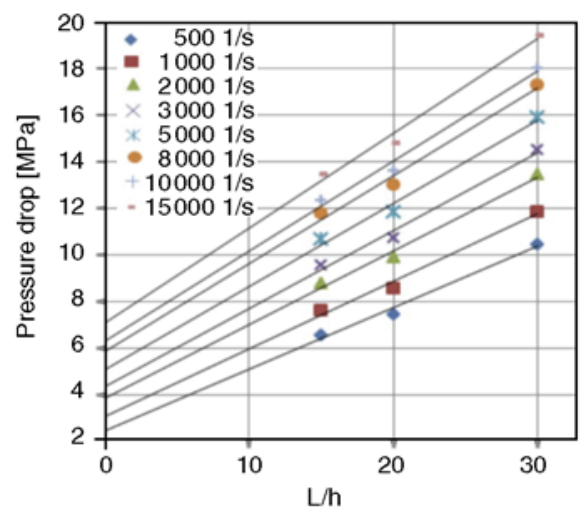

Figure 10. Bagley plot $\left(T_{\text {mat }}=180^{\circ} \mathrm{C}\right)$

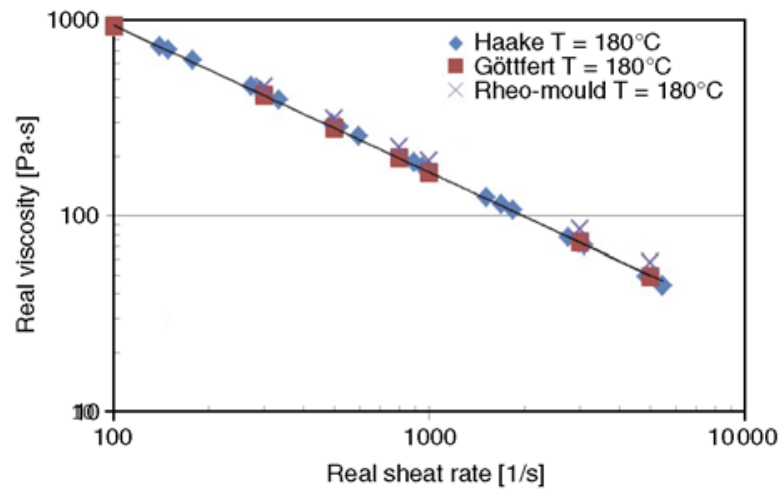

Figure 11. Real viscosity curves

Table 5. The constants of the viscosity curves

\begin{tabular}{|l|c|c|}
\hline \multicolumn{1}{|c|}{ Instrument } & $\boldsymbol{\mu}_{\mathbf{1}}$ & $\mathbf{n}$ \\
\hline Haake & 29706 & 0.250 \\
\hline Göttfert & 30349 & 0.246 \\
\hline Rheo-mould & 29091 & 0.270 \\
\hline
\end{tabular}

instruments. Haake extrusiometer (Miskolc University) and Göttfert Rheograph 25 were used. Correlation of the results of the different instruments is excellent.

The Equation (21) was fit to the calculated real viscosity curves, where $\mu_{1}$ is a constant without real physical meaning. The constants of the equation are listed in the Table 5 (Equation (21)).

$\eta=\mu_{1} \dot{\gamma}^{\mathrm{n}-1}$

\subsection{Investigation of thermal condition by dimensionless quantities}

Calculations were made by the dimensionless quantities (Equations 16-18) using data of the minimum and the maximum flow rate. The mould and material temperature and the cross section of the slit die were changed, too. The results are summarised in Table 6 and Table 7.

Table 4. Constants of the Bagley plots

\begin{tabular}{|c|c|c|c|}
\hline $\begin{array}{c}\dot{\gamma} \\
{[\mathbf{1} / \mathbf{s e c}]}\end{array}$ & $\begin{array}{c}\text { Slope of Bagley plots } \\
{[\mathbf{P a} \cdot \mathbf{s}]}\end{array}$ & $\begin{array}{c}\text { Extrapolated pressure drop } \\
{[\mathbf{P a}]}\end{array}$ & $\begin{array}{c}\text { Linear regression } \\
\left(\boldsymbol{R}^{\mathbf{2}}\right)\end{array}$ \\
\hline 500 & 265175 & 2415699 & 0.9878 \\
\hline 1000 & 290716 & 3046552 & 0.9877 \\
\hline 2000 & 318000 & 3809722 & 0.9874 \\
\hline 3000 & 335000 & 4327469 & 0.9873 \\
\hline 5000 & 357000 & 5065246 & 0.9870 \\
\hline 8000 & 378000 & 5838593 & 0.9868 \\
\hline 10000 & 389000 & 6240761 & 0.9866 \\
\hline 15000 & 408000 & 7034650 & 0.9864 \\
\hline
\end{tabular}


Table 6. Dimensionless quantities $\left(T_{\mathrm{m}}=180^{\circ} \mathrm{C}\right)$

\begin{tabular}{|c|c|c|c|c|c|c|}
\hline Mould & $\mathbf{T}_{\text {mould }}$ & Flow rate & Graetz-number & Nahme-number & Brinkman-number & $\mathbf{p}_{1}[\mathrm{bar}]$ \\
\hline \multirow{6}{*}{$\begin{array}{l}\text { Die } 1 \\
h=2 \mathrm{~mm} \\
w=15 \mathrm{~mm}\end{array}$} & \multirow{2}{*}{$30^{\circ} \mathrm{C}$} & $\min$. & 183 & 25 & 3 & 300 \\
\hline & & $\max$ & 2198 & 1353 & 42 & 350 \\
\hline & \multirow{2}{*}{$90^{\circ} \mathrm{C}$} & $\min$. & 183 & 29 & 1.23 & 173.8 \\
\hline & & $\max$. & 2198 & 681 & 28.6 & 345.4 \\
\hline & \multirow{2}{*}{$180^{\circ} \mathrm{C}$} & $\min$. & - & - & - & 149 \\
\hline & & $\max$ & - & - & - & 290 \\
\hline \multirow{4}{*}{$\begin{array}{l}\text { Die } 2 \\
h=3 \mathrm{~mm} \\
w=15 \mathrm{~mm}\end{array}$} & \multirow{2}{*}{$30^{\circ} \mathrm{C}$} & $\min$. & 274 & 35 & 1.6 & 147.9 \\
\hline & & $\max$. & 4946 & 992 & 44 & 232.7 \\
\hline & \multirow{2}{*}{$90^{\circ} \mathrm{C}$} & $\min$. & 274 & 34 & 2.1 & 136.8 \\
\hline & & $\max$. & 4946 & 1388 & 64.2 & 234.4 \\
\hline \multirow{4}{*}{$\begin{array}{l}\text { Die } 3 \\
h=4 \mathrm{~mm} \\
w=15 \mathrm{~mm}\end{array}$} & \multirow{2}{*}{$30^{\circ} \mathrm{C}$} & $\min$. & 366 & 29 & 1.3 & 90.6 \\
\hline & & $\max$. & 6595 & 807 & 36.6 & 144.8 \\
\hline & \multirow{2}{*}{$90^{\circ} \mathrm{C}$} & $\min$. & 366 & 29 & 1.9 & 88.7 \\
\hline & & $\max$. & 6595 & 859 & 55 & 148.6 \\
\hline
\end{tabular}

Table 7. Dimensionless quantities $\left(T_{\mathrm{m}}=220^{\circ} \mathrm{C}\right)$

\begin{tabular}{|c|c|c|c|c|c|c|}
\hline Mould & $\mathbf{T}_{\text {mould }}$ & Flow rate & Graetz-number & Nahme-number & Brinkman-number & $\mathbf{p}_{1}[\mathrm{bar}]$ \\
\hline \multirow{6}{*}{$\begin{array}{l}\text { Die } 1 \\
h=2 \mathrm{~mm} \\
w=15 \mathrm{~mm}\end{array}$} & \multirow{2}{*}{$30^{\circ} \mathrm{C}$} & $\min$. & 183 & 26 & 2 & 260.5 \\
\hline & & $\max$. & 2198 & 570 & 44 & 318.3 \\
\hline & \multirow{2}{*}{$90^{\circ} \mathrm{C}$} & $\min$. & 183 & 20 & 1.36 & 150.9 \\
\hline & & $\max$. & 2198 & 520 & 34 & 215.4 \\
\hline & \multirow{2}{*}{$220^{\circ} \mathrm{C}$} & $\min$. & - & - & - & 106 \\
\hline & & $\max$. & - & - & - & 270 \\
\hline \multirow{4}{*}{$\begin{array}{l}\text { Die } 2 \\
h=3 \mathrm{~mm} \\
w=15 \mathrm{~mm}\end{array}$} & \multirow{2}{*}{$30^{\circ} \mathrm{C}$} & $\min$. & 274 & 24 & 1.41 & 127.4 \\
\hline & & $\max$. & 4946 & 563 & 33 & 170.3 \\
\hline & \multirow{2}{*}{$90^{\circ} \mathrm{C}$} & $\min$. & 274 & 29,2 & 1.26 & 114.8 \\
\hline & & $\max$. & 4946 & 879 & 38 & 196.7 \\
\hline \multirow{4}{*}{$\begin{array}{l}\text { Die } 3 \\
h=4 \mathrm{~mm} \\
w=15 \mathrm{~mm}\end{array}$} & \multirow{2}{*}{$30^{\circ} \mathrm{C}$} & $\min$. & 366 & 23 & 0.92 & 74.4 \\
\hline & & $\max$. & 6595 & 608 & 24.4 & 115.0 \\
\hline & \multirow{2}{*}{$90^{\circ} \mathrm{C}$} & $\min$. & 366 & 15 & 0.7 & 46.3 \\
\hline & & $\max$. & 6595 & 700 & 17 & 119.6 \\
\hline
\end{tabular}

It can be seen that the Graetz number is larger than 100 in every set up. As the calculated Nahme numbers are much larger than 1 , the cross heat flow is much smaller than the axial heat flow. However, it should be emphasised that on the cavity wall a frozen polymeric layer was developed affecting the efficient cross-section of the flow. This thickness is proportional to the pressure drop; the higher the pressure drop is, the thicker the frozen layer is. According to the measured and calculated values (Table 6, Table 7), increasing the height of the cavity the effect of the mould temperature on the pressure becomes smaller meaning that the frozen layer has less effect on the flow. Because of this frozen layer, the flow cross section must be smaller, and it has effect on the pressure drop and the dissipation heat, too. Applying the thinnest die $(h=2 \mathrm{~mm})$ and cooled mould temperature, the pressure drop was the highest.

Brinkman number was larger than one in every setup (except two measurements with die 3 at $220^{\circ} \mathrm{C}$ ). This means that the dissipation heat has a larger effect on the viscosity than the perpendicular heat transfer.

The measured pressure drop between two sensors ( $\Delta p_{\text {measured }}$, the average temperature rising by dissipation heat $\left(\Delta T_{\text {dissip }}\right)$, the real viscosity $\left(\eta_{\text {measured }}\right)$, the viscosity decrease by dissipation heat $\left(\eta_{\text {dissip }}\right)$, the viscosity decrease by pressure ( $\left.\eta_{\text {pressure }}\right)$ and the corrected pressure drop ( $\left.\Delta p_{\text {corrected }}\right)$ are summarised in Table 8.

The effect of the pressure and the temperature $\left(\Delta p_{\text {corrected }}\right)$ were calculated by Laun. $\Delta p_{\text {measured }}$ and $\Delta p_{\text {corrected }}$ are in good correlation. The average dif- 
Table 8. Effect of the dissipation heat and the pressure on viscosity

\begin{tabular}{|l|c|c|c|c|c|}
\hline \multirow{2}{*}{} & $\mathbf{T}_{\text {material }}\left[{ }^{\circ} \mathbf{C}\right]$ & $\mathbf{1 8 0}$ & $\mathbf{1 8 0}$ & $\mathbf{2 2 0}$ & $\mathbf{2 2 0}$ \\
\cline { 2 - 6 } & $\mathbf{T}_{\text {mould }}\left[{ }^{\circ} \mathbf{C}\right]$ & $\mathbf{3 0}$ & $\mathbf{1 8 0}$ & $\mathbf{3 0}$ & $\mathbf{2 2 0}$ \\
\cline { 2 - 6 } & \multicolumn{5}{|c|}{$\mathbf{Q}$} \\
\hline $\begin{array}{l}\Delta p_{\text {measured }} \\
{[\mathrm{MPa}]}\end{array}$ & min. & 10.67 & 12.54 & 11.42 & 8.53 \\
\cline { 2 - 6 } $\begin{array}{l}\Delta T_{\text {dissip. }} \\
{\left[{ }^{\circ} \mathrm{C}\right]}\end{array}$ & max. & 15.95 & 28.24 & 14.9 & 20.65 \\
\cline { 2 - 6 } & max. & 5.4 & 6.33 & 5.7 & 4.31 \\
\hline$\eta_{\text {measured }}$ & min. & 267 & 313.5 & 285.6 & 213.3 \\
\cline { 2 - 6 }$[\mathrm{Pa} \cdot \mathrm{s}]$ & max. & 20 & 35.3 & 18.59 & 25.8 \\
\hline$\eta_{\text {dissip }}$ & min. & 232 & 265.8 & 245.8 & 190.7 \\
\cline { 2 - 6 }$[\mathrm{Pa} \cdot \mathrm{s}]$ & max. & 16.1 & 24.35 & 15.3 & 19.67 \\
\hline$\eta_{\text {pressure }}$ & min. & 277.6 & 328.2 & 297.8 & 220 \\
\cline { 2 - 6 }$[\mathrm{Pa} \cdot \mathrm{s}]$ & max. & 21.2 & 39.14 & 19.7 & 27.8 \\
\hline$\Delta p_{\text {corrected }}$ & min. & 11.4 & 13.47 & 12.23 & 9.03 \\
\cline { 2 - 6 }$[\mathrm{MPa}]$ & max. & 17.2 & 28.1 & 16 & 22.04 \\
\hline
\end{tabular}

ference is less than $6 \%$. This good correlation means that the dissipation heat equalises the effect of the pressure on the viscosity of the melt.

\section{Conclusions}

A new type of rheological measuring system has been designed and manufactured. The special injection mould can be used to determine the flow curve of molten polymers during the injection moulding process. If the mould is heated up to the processing temperature, the flow condition is close to adiabatic, especially by higher flow rate. It was found that the mould temperature has a smaller effect on the flow condition if the cross section is bigger than $2 \mathrm{~mm}$.

\section{References}

[1] Clavería I., Javierre C., Ponz L.: Method for generation of rheological model to characterize non-conventional injection molding by means of spiral mold. Journal of Materials Processing Technology, 162-163, 477-483 (2005).

DOI: $10.1016 /$ j.jmatprotec.2005.02.065

[2] Chen S. C., Tsai R. I., Chein R. D., Lin T. K.: Preliminary study of polymer melt rheological behavior flowing through micro-channels. International Communications in Heat and Mass Transfer, 32, 501-510 (2005). DOI: 10.1016/j.icheatmasstransfer.2004.07.004
[3] Chen C-S., Chen S-C., Liaw W-L., Chien R-D.: Rheological behavior of POM polymer melt flowing through micro-channels. European Polymer Journal, 44, 18911898 (2008).

DOI: $10.1016 /$ j.eurpolymj.2008.03.007

[4] Benhadou M., Haddout A., Villoutreix G.: Injection of polypropylene reinforced with short glass fibers: Rheological behavior. Journal of Reinforced Plastics and Composites, 26, 1357-1366 (2007).

DOI: $10.1177 / 0731684407079735$

[5] Bariani P. F., Salvador M., Lucchetta G.: Development of a test method for the rheological characterization of polymers under the injection molding process conditions. Journal of Materials Processing Technology, 191, 119-122 (2007).

DOI: $10.1016 /$ j.jmatprotec.2007.03.089

[6] Haddout A., Villoutreix G.: Polymer melt rheology at high shear rates. International Polymer Processing, 2000, 291-296 (2000).

[7] Szücs A.: Study of non-isothermal mould filling. in 'Proceedings of International Doctoral Seminar, Smolenice, Slovakia', 467-474 (2010).

[8] Belina K., Szűcs A.: Investigation of polymer flow during filling stage. in 'Proceedings of PPS2006 conference, Pretoria, South Africa' p.4 (2006).

[9] Chang D. H.: Rheology in polymer processing. Academic Press, New York (1976).

[10] Son Y.: Determination of shear viscosity and shear rate from pressure drop and flow rate relationship in a rectangular channel. Polymer, 48, 632-637 (2007).

DOI: $10.1016 /$ j.polymer.2006.11.048

[11] Hay G., Mackay M. E., McGlashan S. A., Park Y.: Comparison of shear stress and wall slip measurement techniques on a linear low density polyethylene. Journal of Non-Newtonian Fluid Mechanics, 92, 187-201 (2000).

DOI: $10.1016 / \mathrm{S} 0377-0257(00) 00096-3$

[12] Halász L.: Control methods in polymer processing. Elsevier, Amsterdam (1994).

[13] Laun H. M.: Pressure dependent viscosity and dissipative heating in capillary rheometry of polymer melts. Rheologica Acta, 42, 295-308 (2003). DOI: $10.1007 / \mathrm{s} 00397-002-0291-6$

[14] Laun H. M.: Polymer melt rheology with a slit die. Rheologica Acta, 22, 171-185 (1983). DOI: $10.1007 / \mathrm{BF} 01332370$ 